\title{
Activation of Sphalerite by Ammoniacal Copper Solution in Froth Flotation
}

\author{
Xian Xie, ${ }^{1,2}$ Kai Hou, ${ }^{3}$ Bo Yang, ${ }^{1,2}$ and Xiong Tong ${ }^{1,2}$ \\ ${ }^{1}$ Faculty of Land and Resource Engineering, Kunming University of Science and Technology, Kunming, Yunnan 650093, China \\ ${ }^{2}$ State Key Laboratory of Complex Nonferrous Metal Resources Clean Utilization, Kunming 650093, China \\ ${ }^{3}$ School of Minerals Processing and Bioengineering, Central South University, Changsha 410083, China \\ Correspondence should be addressed to Xiong Tong; xiongtong2000@yahoo.com
}

Received 13 October 2015; Accepted 15 February 2016

Academic Editor: Davide Vione

Copyright (c) 2016 Xian Xie et al. This is an open access article distributed under the Creative Commons Attribution License, which permits unrestricted use, distribution, and reproduction in any medium, provided the original work is properly cited.

\begin{abstract}
The activation of sphalerite particles by ammoniacal copper solution (ACS) was investigated in this study. This microflotation study was conducted on a single sphalerite mineral with the particles size of $38 \mu \mathrm{m}$ to $75 \mu \mathrm{m}$. Results showed that ACS has somewhat better activation effect than copper sulphate (a traditional activator) with sodium isobutyl xanthate as the collector. Agglomeration observation, contact angle measurement, and X-ray photoelectron spectroscopy measurement results of sphalerite particles verified the superiority of this new activator. Therefore, the substitution of copper sulphate with ACS would increase the separation efficiency not only in marmatite flotation but also in sphalerite flotation.
\end{abstract}

\section{Introduction}

Naturally occurring zinc minerals, such as sphalerite, are abundant in China. According to the United States Geological Survey, geologists have confirmed total reserves of 430 million tons of zinc resources (the second largest in the world) in China. China is the largest zinc producer, and 5 million tons was produced in 2013. However, given the unique geological structure of China, sphalerite is commonly associated with metallic sulphide ores, such as chalcopyrite, galena, marmatite, pyrite, and pyrrhotite, which makes it difficult to differentiate sphalerite efficiently $[1,2]$.

Usually, copper sulphate is used in zinc flotation as an appropriate activator. The activation mechanisms of sphalerite with $\mathrm{Cu}^{2+}$ or $\mathrm{Cu}(\mathrm{OH})_{2}$ have been investigated using different analysis and experimental methods, such as microflotation, electrochemistry, atomic force microscopy, $\mathrm{X}$-ray photoelectron spectroscopy (XPS), scanning electron microscopy with energy dispersive X-ray spectroscopy, and density functional theory computation [3-8]. Many researchers believed that chemisorption and substitution reactions occur among $\mathrm{Zn}, \mathrm{S}$, and $\mathrm{Cu}$ atoms or $\mathrm{Cu}(\mathrm{OH})_{2}$ molecule during activation flotation. However, the copperammonia complex has not been extensively investigated.
Recently, ammoniacal copper solution (ACS) was observed to have a better effect on the activation of marmatite in a weak alkaline situation compared with copper sulphate, ammonium chloride, and lead nitrate $[9,10]$. ACS has been commercially used in Dulong Mine of Yunnan Province in the southern part of China [11]. Because of the similarity between marmatite and sphalerite, we assumed that ACS might also be appropriate for the selective flotation of sphalerite. In this study, we determined whether ACS can be an effective activator for sphalerite.

\section{Experimental}

2.1. Materials. Sphalerite was obtained from Dulong Mine, Yunnan Province, China. The sample was crushed, handsorted, dry-ground in a mechanical agate mortar and pestle, and dry-screened to obtain sphalerite particles of $38 \mu \mathrm{m}$ to $75 \mu \mathrm{m}$. The X-ray diffraction (XRD) patterns of the sample showed that sphalerite was of high purity, with no impurity peaks detected (Figure 1). The sphalerite sample assayed $64.96 \% \mathrm{Zn}, 33.83 \% \mathrm{~S}, 0.89 \% \mathrm{Fe}, 0.26 \% \mathrm{~Pb}$, and $0.03 \% \mathrm{Cu}$. The XRD pattern of sample was conducted by using a D/max2200 X-ray diffractometer (Rigaku, Japan). 


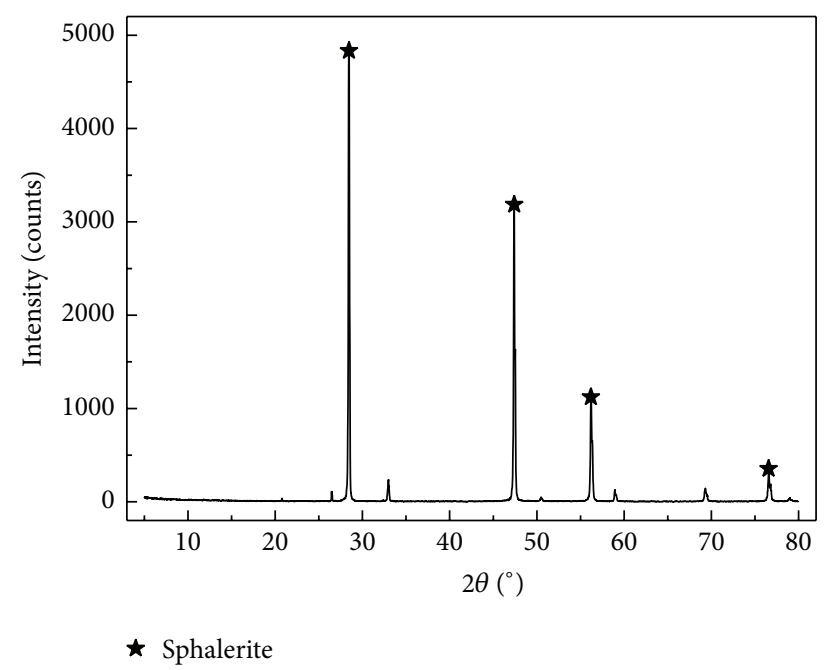

FIGURE 1: XRD pattern of the sphalerite sample.

2.2. Reagents. Copper sulphate pentahydrate $\left(\mathrm{CuSO}_{4} \cdot 5 \mathrm{H}_{2} \mathrm{O}\right.$; Kunming Chemical Reagent Co., Ltd., China), ammonia chloride $\left(\mathrm{NH}_{4} \mathrm{Cl}\right.$; Kunming Chemical Reagent Co., Ltd., China), sodium isobutyl xanthate (SIBX; $\mathrm{C}_{5} \mathrm{H}_{9} \mathrm{OS}_{2} \mathrm{Na}$; Yunnan Hualian Zinc \& Indium Stock Co., Ltd., China), and sodium hydroxide ( $\mathrm{NaOH}$; Chengdu Chemical Reagents Co., Ltd., China) were used as received. Distilled water was used throughout the tests. SIBX was purified by recrystallising $100 \mathrm{~g}$ of xanthate into $1,000 \mathrm{~mL}$ of warm acetone at $40^{\circ} \mathrm{C}$ in a water bath, stirred for a few minutes, and precipitated by ether following an established method. ACS was prepared in the laboratory. A detailed description of the preparation of ACS was provided by Tong et al. [9].

\subsection{Experimental Methods}

2.3.1. Contact Angle Measurements. Contact angle tests were conducted at $22^{\circ} \mathrm{C}$ to $25^{\circ} \mathrm{C}$ room temperature and $67 \%$ relative humidity. Pure sphalerite discs were polished mechanically and manually burnished with fine grit sandpaper to produce a smooth surface. Then, a microsyringe was used to drop $5 \mu \mathrm{L}$ distilled water onto the sphalerite surface with or without reagents. Finally, contact angle measurement was conducted with a JY-82-type contact angle analyser manufactured by Chengde Test Factory, China. The reagent concentration and action duration were the same as the most optimal conditions in flotation operation. Each surface was measured thrice on average.

2.3.2. XPS Measurements. The Quantera II microprobe (Scott Internet Technology Co., Ltd.) was used in the XPS measurements conducted at the Analysis and Test Center of Kunming University of Science and Technology. Copper sulphate or ACS at a concentration of $1.0 \times 10^{-4} \mathrm{~mol} / \mathrm{L}$ was added to soak the test sample for $5 \mathrm{~min}$. Then, SIBX was added for $1 \mathrm{~min}$. Finally, the sample was dried and tested.

2.3.3. Small-Scale Flotation Test. The flotation tests were conducted in a modified Hallimond tube, as described in

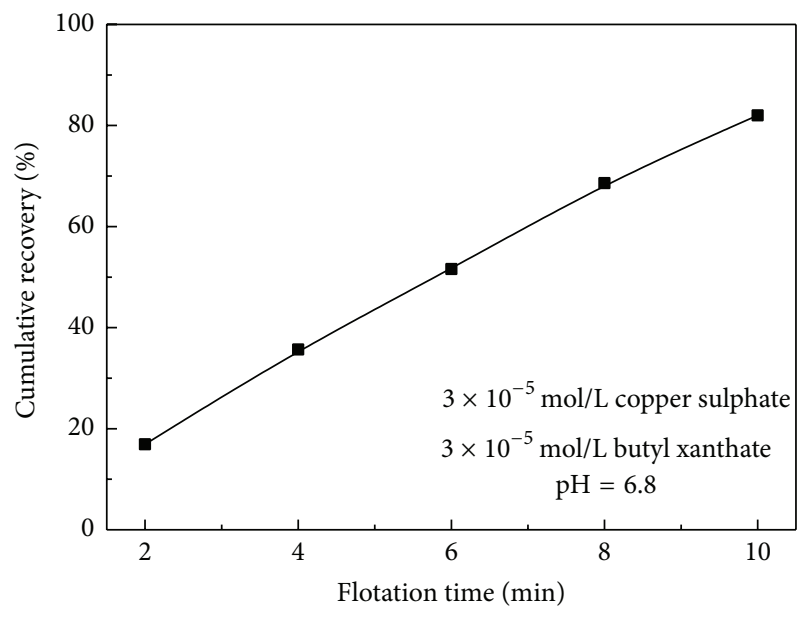

FIGURE 2: Effect of flotation duration.

detail by Cao and Liu [12]. In this tube, a sintered glass frit with a pore size of $1.6 \mu \mathrm{m}$ was fitted at the base, on which a stirring bar was used to agitate the flotation pulp. Gas flows through the frit base to generate small bubbles that float up to a narrow throat, which connects the flotation tube to a collection bulb. The narrow throat allows only one bubble to pass at a time. Thus, mechanical entrainment is minimised. In a typical test, $1.1 \mathrm{~g}$ of sphalerite with the particles size of $38 \mu \mathrm{m}$ to $75 \mu \mathrm{m}$ was firstly mixed with distilled water in a $50 \mathrm{~mL}$ beaker; then, the $\mathrm{pH}$ of pulp was adjusted by using hydrochloric acid or sodium hydroxide. After that, a certain amount of either $0.1 \mathrm{~mol} / \mathrm{L} \mathrm{CuSO}_{4} \cdot 5 \mathrm{H}_{2} \mathrm{O}$ or ACS was added and stirred for $5 \mathrm{~min}$. After the addition of SIBX, the pulp was quickly transferred to the Hallimond tube and floated for $10 \mathrm{~min}$ with a $\mathrm{N}_{2}$ flow rate of $0.01 \mathrm{dm}^{3} / \mathrm{min}$. During the conditioning process, the stirring speed was maintained at $1,300 \mathrm{rad} / \mathrm{min}$. Finally, the mixed pulp was transferred to the Hallimond tube, with an agitation speed of $1,000 \mathrm{rad} / \mathrm{min}$. The floated and nonfloated products were filtered, dried, and weighed. Then, the recovery of each flotation test was calculated by using the following equation: Recovery = weight of the floated sample/weight of the nonfloated and floated sample.

\section{Results and Discussion}

3.1. Effect of Flotation Duration. Figure 2 shows the effect of flotation duration on sphalerite cumulative recovery in the presence of the activator and collector. The result shows that $6 \mathrm{~min}$ is the appropriate duration to float sphalerite because a longer duration would lead to $100 \%$ recovery, which would result in loss of comparability.

3.2. Effect of Activator Types and Their Dosages. The effect of different activator types and their dosages on the recovery of sphalerite is shown in Figure 3. Two types of activators, that is, copper sulphate and ACS, at different dosages were tested. The results showed that recovery increased with increasing activator dosage and reached its peak at a dosage of $4.0 \times$ $10^{-5} \mathrm{~mol} / \mathrm{L}$ for copper sulphate and $5.0 \times 10^{-5} \mathrm{~mol} / \mathrm{L}$ for ACS. 


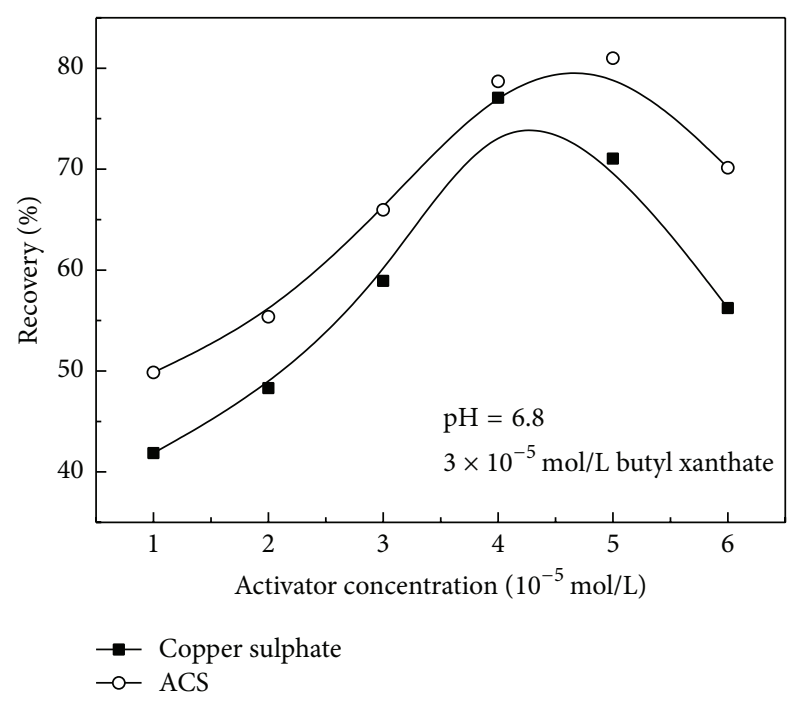

Figure 3: Effects of activator types and their concentration on sphalerite recovery.

With continued increase in activator dosage, the recoveries of sphalerite with the two activators decreased. Popov and Vučinić determined that, with a high $\mathrm{Cu}^{2+}$ concentration, excess $\mathrm{Cu}^{2+}$ would react with xanthate, thereby decreasing the concentration of xanthate, which reacted with sphalerite. Thus, the recovery of sphalerite was reduced. Figure 3 shows that, at the same activator dosage, ACS exhibits a certain advantage on the recovery of sphalerite with $3.0 \times 10^{-5} \mathrm{~mol} / \mathrm{L}$ SIBX at $\mathrm{pH}$ 6.8. The peak recovery is $77.1 \%$ with $4.0 \times$ $10^{-5} \mathrm{~mol} / \mathrm{L}$ copper sulphate. By contrast, the peak recovery is $80.99 \%$ with $5.0 \times 10^{-5} \mathrm{~mol} / \mathrm{L}$ ACS.

3.3. Effect of SIBX Dosage. Different dosages of SIBX were used during the flotation experiments. The optimal activator dosages $\left(4.0 \times 10^{-5} \mathrm{~mol} / \mathrm{L}\right.$ copper sulphate and $5.0 \times$ $10^{-5} \mathrm{~mol} / \mathrm{L}$ ACS) were used to activate sphalerite. The effect of SIBX dosage on $\mathrm{Zn}$ recovery during flotation is shown in Figure 4. The recoveries increased with increasing SIBX dosage and reached the maximum value at the SIBX dosage of $4.0 \times 10^{-5} \mathrm{~mol} / \mathrm{L}$. At this SIBX dosage, the recovery of sphalerite reached $87.5 \%$ when copper sulphate was used as activator and $91.8 \%$ when ACS was used as activator at $\mathrm{pH}$ 6.8. This finding suggests that ACS exhibited better activator effect than copper sulphate under the same conditions.

3.4. Effect of $p H$. Using the aforementioned optimised activators and SIBX dosages, the effect of $\mathrm{pH}$ on the recovery of sphalerite was also investigated. An "M-" type curve is shown in Figure 5. Two peaks appear at $\mathrm{pH}$ values of 6 and 10. Under strong acidic conditions $(\mathrm{pH}<4.0)$, SIBX was decomposed rapidly, which resulted in low recovery. By contrast, under strong alkaline conditions $(\mathrm{pH}>12.0)$, low $\mathrm{Zn}$ recovery was probably caused by the excess copper hydroxide film, which led to hydrophilicity of the sphalerite surface [8]. Under a weakly acidic condition, both activators showed high recovery. Moreover, ACS was better than copper sulphate in activating sphalerite. Tong et al. calculated the species

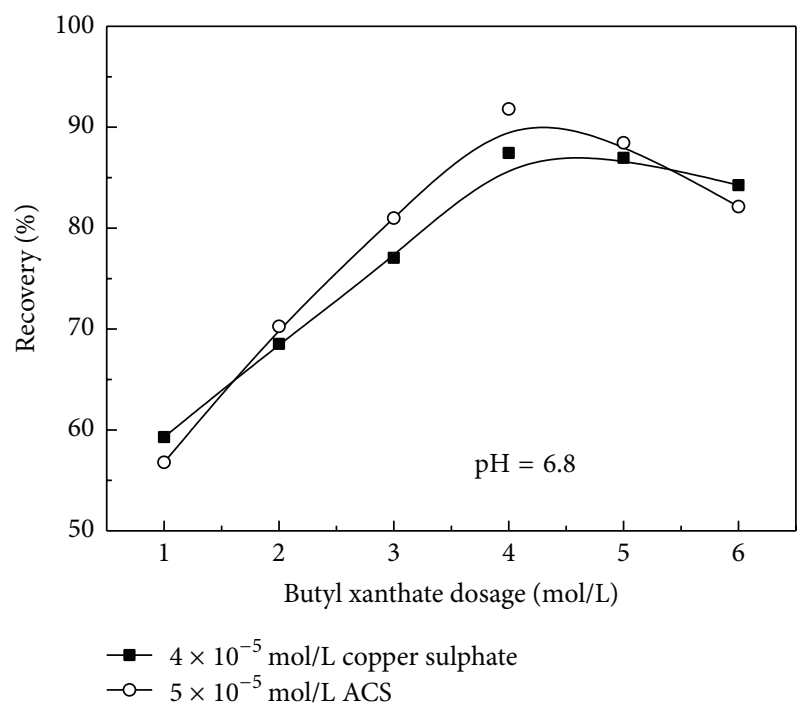

FIGURE 4: Effects of SIBX dosage on sphalerite recovery.

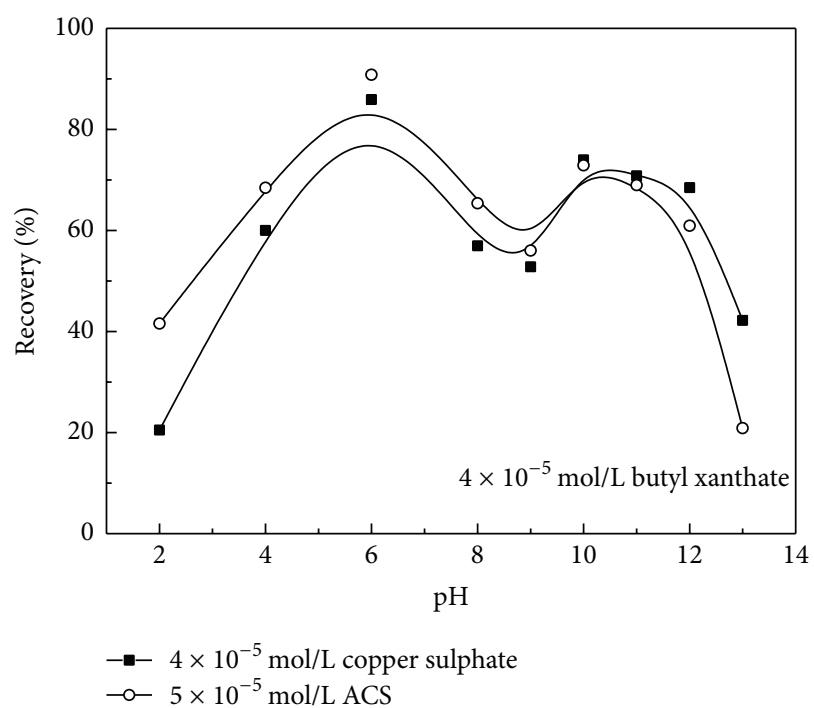

FIGURE 5: Effects of $\mathrm{pH}$ on sphalerite recovery (sulphuric acid and sodium hydroxide solution as $\mathrm{pH}$ regulator).

distribution of copper-ammonia complexes as a function of $\mathrm{pH}$ at $[\mathrm{Cu}(\mathrm{II})]_{\text {Total }}=0.1 \mathrm{mmol} / \mathrm{L}$ and $\left[\mathrm{NH}_{3}\right]_{\text {Total }}=0.4 \mathrm{mmol} / \mathrm{L}$ based on the equations and equilibrium constants [9]. This activation might have originated from the adsorption of the copper-ammonia complexes, $\mathrm{CuNH}_{3}{ }^{2+}$ and $\mathrm{Cu}\left(\mathrm{NH}_{3}\right)_{2}{ }^{2+}$, onto the surfaces of marmatite and sphalerite minerals at $\mathrm{pH}$ $<10$. When $\mathrm{pH}$ was in the range of 10 to $14, \mathrm{Cu}^{2+}$ was likely the main activator of sphalerite.

3.5. Agglomeration Observation. Agglomerations of less than $38 \mu \mathrm{m}$ sphalerite particles before and after the addition of ACS (or $\mathrm{CuSO}_{4}$ ) and SIBX were observed and photographed using the BH200 microscope. Figure 6 shows sphalerite without reagents. Figure 7 shows the hydrophobic aggregation of sphalerite with ACS and SIBX treatment. In the flotation 


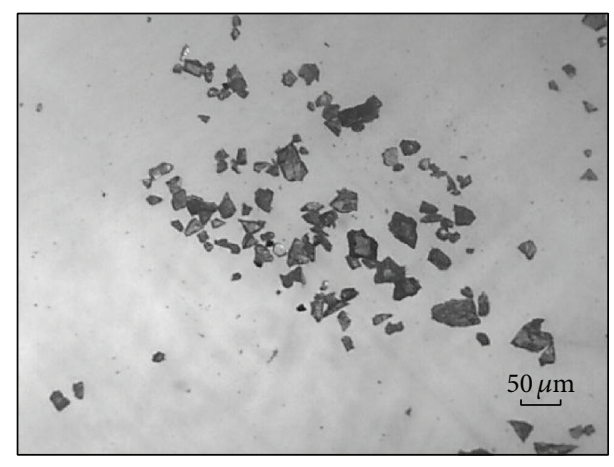

FIGURE 6: Sphalerite with no reagent treated.

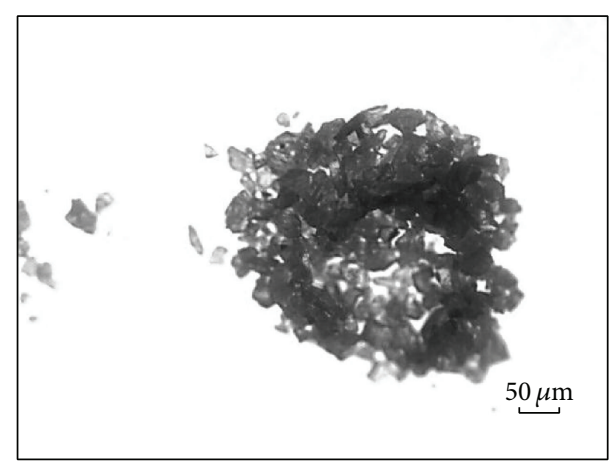

FIGURE 7: Hydrophobic aggregation photo of sphalerite (treated with ACS and SIBX).

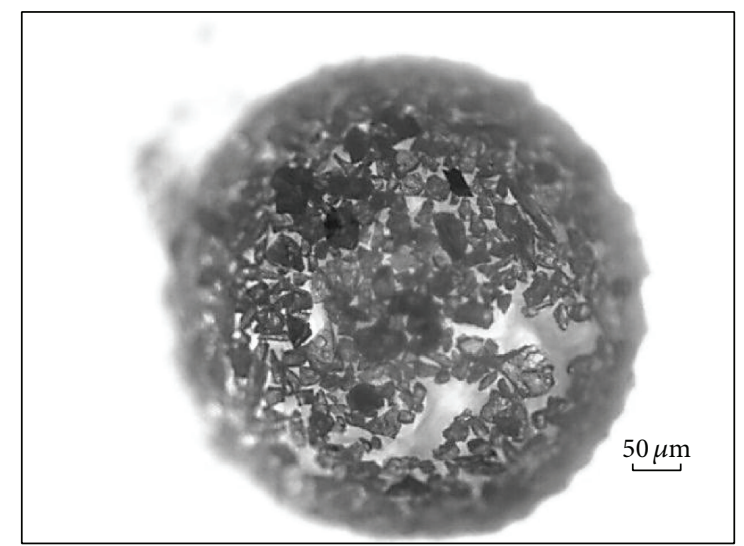

FIGURE 8: Microbubble with adhering sphalerite (treated with ACS and SIBX).

process, some microbubbles with adhering sphalerite were also observed (see Figure 8). Without reagents, the sphalerite particles were in the dispersed state. However, agglomerates were observed after treatment with the activators ACS and SIBX. The aggregation of sphalerite was observed by Mirnezami et al. [13], at a $\mathrm{pH}$ range of 7 to 9. However, with the activator and collector, the agglomeration of sphalerite has not been observed. The agglomeration of sphalerite may benefit the flotation process. During flotation, we observed some microbubbles with adhering sphalerite. These bubbles
TABLE 1: Contact angles of the sphalerite with different agents disposed $/^{\circ}$.

\begin{tabular}{lcc}
\hline Treatment & $\begin{array}{c}\text { Experiment } \\
\text { value }\end{array}$ & $\begin{array}{c}\text { Added value (compared } \\
\text { with the reagents untreated } \\
\text { surface) }\end{array}$ \\
\hline No & 62.75 & 0 \\
Copper sulphate & 67.72 & 4.97 \\
Copper sulphate + & 74.28 & 11.53 \\
SIBX & 70.50 & 0 \\
\hline No & 73.55 & 3.05 \\
Copper sulphate & 77.58 & 7.08 \\
Copper sulphate + & 69.00 & 0 \\
SIBX & 76.45 & 7.45 \\
No & 81.80 & 12.80 \\
ACS & 60.63 & 0 \\
ACS + SIBX & 70.38 & 9.75 \\
No & 79.17 & 18.54 \\
ACS & & \\
ACS + SIBX & &
\end{tabular}

were different from normal bubbles. The microbubbles were smaller and more stable, and we were able to pick them out with a glass rod and place them on a slide. The microbubbles cannot easily be fractured. This finding suggests that sphalerite particles tended to form hydrophobic agglomerates and stable microbubbles with ACS and SIBX, which can benefit the flotation of sphalerite.

3.6. Contact Angle Measurements. Contact angle measurement is one of the analysis methods used to determine the hydrophobicity of minerals. A solid-liquid-gas interface with a large contact angle had satisfactory water repellency and floatability. The results of contact angle measurement are shown in Table 1 . With the addition of reagents, the contact angle values increased to different degrees. Comparing the four contact angles in Table 1, we determined that the latter two contact angles with larger value would allow for better floatability. This finding suggests that sphalerite with ACS and SIBX had a more hydrophobic surface, leading to better floatability.

3.7. XPS Measurements. The binding energy and relative concentration of elements before and after the reactions are shown in Table 2 . The $2 \mathrm{p}$ spectra are shown in Figures 9, 10, and 11.

Table 2 shows that the relative concentration of copper sulphate is $0.2 \%$ higher than that of ACS on the sphalerite surface; however, this finding could not explain the stronger force between copper sulphate and sphalerite surface. Some of the copper ions may have entered the intracrystal sphalerite, leading to bulk adsorption. Based on binding energy (Figure 9), a difference of $0.18 \mathrm{eV}$ was obtained $(932.49 \mathrm{eV}$ for copper sulphate + sphalerite and $932.67 \mathrm{eV}$ for ACS + sphalerite), which was less than the test error. As such, we 
TABLE 2: Binding energy and relative concentration of elements before and after reactions.

\begin{tabular}{lccc}
\hline Samples & $\begin{array}{c}\text { Atomic } \\
\text { orbital }\end{array}$ & $\begin{array}{c}\text { Binding } \\
\text { energy/eV }\end{array}$ & $\begin{array}{c}\text { Relative } \\
\text { concentration/\% }\end{array}$ \\
\hline Copper sulphate + & Cu2p & 932.49 & 9.3 \\
SIBX + sphalerite & Zn2p & 1021.56 & 18.6 \\
& S2p & 161.29 & 20.2 \\
\hline ACS + SIBX + & Cu2p & 932.67 & 9.1 \\
sphalerite & Zn2p & 1021.64 & 17.0 \\
& S2p & 161.63 & 21.1 \\
\hline
\end{tabular}

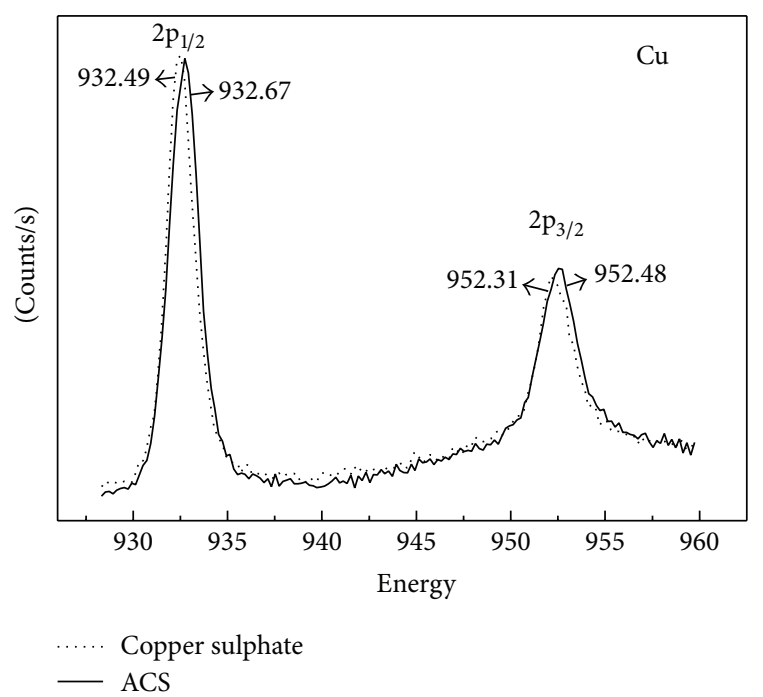

Figure 9: $2 \mathrm{p}$ spectra of $\mathrm{Cu}$ on sphalerite in the presence of different activator and collector butyl xanthate.

could infer that after the addition of different reagents to the activators the same valence stage may be attained.

Table 2 and Figure 10 show that the relative $\mathrm{Cu}$ atom concentration for copper sulphate activation is $1.6 \%$ higher than that ACS activation on the sphalerite surface. This finding suggests that, for the $\mathrm{Cu}$ replacement ability substituting the surface $\mathrm{Zn}$ atom of sphalerite, ACS was stronger than that of copper sulphate. ACS and copper sulphate also have the same valence stage because of their similar binding energy.

Table 2 and Figure 11 show that the binding energy of ACS had a $0.34 \mathrm{eV}$ positive deviation compared with that of copper sulphate. This finding suggests that ACS had a stronger oxidation ability. As such, ACS could oxidise surface sphalerite more effectively, thereby resulting in the production of more hydrophobic sulphur and leading to an improvement of the flotation process.

\section{Conclusions}

(1) The microflotation test conducted in this study has shown that sphalerite flotation can be effectively activated by ACS at $\mathrm{pH} 6$ to 9 , which is somewhat better than copper sulphate.

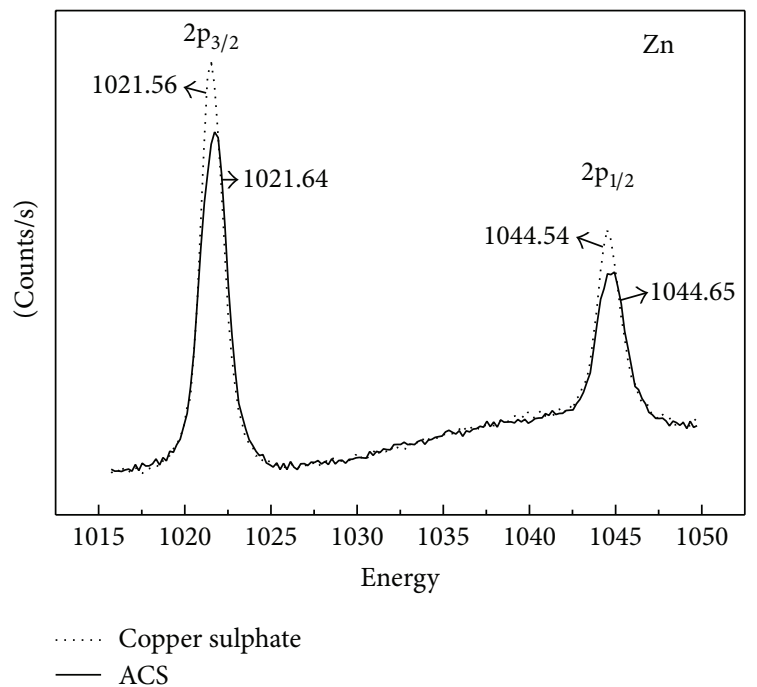

FIgURE 10: $2 \mathrm{p}$ spectra of $\mathrm{Zn}$ on sphalerite in the presence of different activator and collector butyl xanthate.

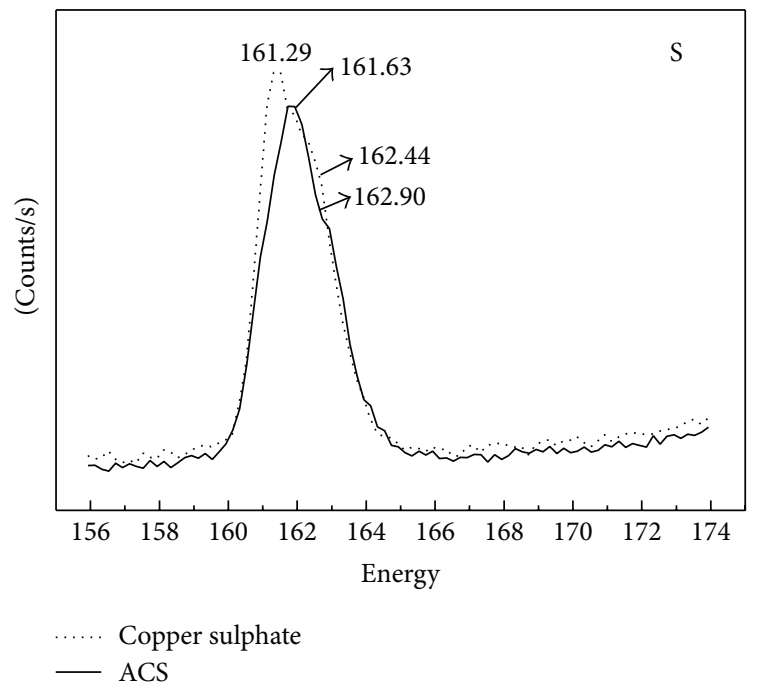

Figure 11: 2p spectra of $S$ on sphalerite in the presence of different activator and collector butyl xanthate.

(2) The agglomeration with ACS and SIBX, contact angle measurement, and XPS measurement results verified the superiority of this new activator. Therefore, the substitution of copper sulphate with ACS would increase the separation efficiency in marmatite and sphalerite flotation.

\section{Competing Interests}

The authors declare that they have no competing interests.

\section{Acknowledgments}

The authors are grateful for the financial support from the Applied Basic Research Key Projects of Yunnan Province 
(Grant no. 2014FA027) and the National Natural Science Foundation of China (Grant no. 51174103).

\section{References}

[1] W. Sun, J. Su, G. Zhang, and Y. Hu, "Separation of sulfide lead-zinc-silver ore under low alkalinity condition," Journal of Central South University, vol. 19, no. 8, pp. 2307-2315, 2012.

[2] Y. Xu, W. Qin, and H. Liu, "Mineralogical characterization of tin-polymetallic ore occurred in Mengzi, Yunnan Province, China," Transactions of Nonferrous Metals Society of China, vol. 3, pp. 725-730, 2012.

[3] S. R. Popov and D. R. Vučinić, "The ethylxanthate adsorption on copper-activated sphalerite under flotation-related conditions in alkaline media," International Journal of Mineral Processing, vol. 30, no. 3-4, pp. 229-244, 1990.

[4] J. Liu, S. Wen, X. Chen, S. Bai, D. Liu, and Q. Cao, "DFT computation of $\mathrm{Cu}$ adsorption on the $\mathrm{S}$ atoms of sphalerite (1 10) surface," Minerals Engineering, vol. 46-47, pp. 1-5, 2013.

[5] A. N. Buckley, R. Woods, and H. J. Wouterlood, "An XPS investigation of the surface of natural sphalerites under flotationrelated conditions," International Journal of Mineral Processing, vol. 26, no. 1-2, pp. 29-49, 1989.

[6] A. R. Gerson, A. G. Lange, K. E. Prince, and R. St. C. Smart, "The mechanism of copper activation of sphalerite," Applied Surface Science, vol. 137, no. 1-4, pp. 207-223, 1999.

[7] D. Fornasiero and J. Ralston, "Effect of surface oxide/hydroxide products on the collectorless flotation of copper-activated sphalerite," International Journal of Mineral Processing, vol. 78, no. 4, pp. 231-237, 2006.

[8] A. P. Chandra and A. R. Gerson, "A review of the fundamental studies of the copper activation mechanisms for selective flotation of the sulfide minerals, sphalerite and pyrite," Advances in Colloid and Interface Science, vol. 145, no. 1-2, pp. 97-110, 2009.

[9] X. Tong, S. Song, J. He, F. Rao, and A. Lopez-Valdivieso, "Activation of high-iron marmatite in froth flotation by ammoniacal copper(II) solution," Minerals Engineering, vol. 20, no. 3, pp. 259-263, 2007.

[10] X. Xie, X. Tong, Y. Cui, and D. Wu, "Study on activation performance of several kinds of activators on marmatite," Metal Mine, vol. 12, pp. 50-53, 2010 (Chinese).

[11] X. Tong, S. Song, J. He, and A. Lopez-Valdivieso, "Flotation of indium-beard marmatite from multi-metallic ore," Rare Metals, vol. 27, no. 2, pp. 107-111, 2008.

[12] M. Cao and Q. Liu, "Reexamining the functions of zinc sulfate as a selective depressant in differential sulfide flotation-the role of coagulation," Journal of Colloid and Interface Science, vol. 301, no. 2, pp. 523-531, 2006.

[13] M. Mirnezami, L. Restrepo, and J. A. Finch, "Aggregation of sphalerite: role of zinc ions," Journal of Colloid and Interface Science, vol. 259, no. 1, pp. 36-42, 2003. 

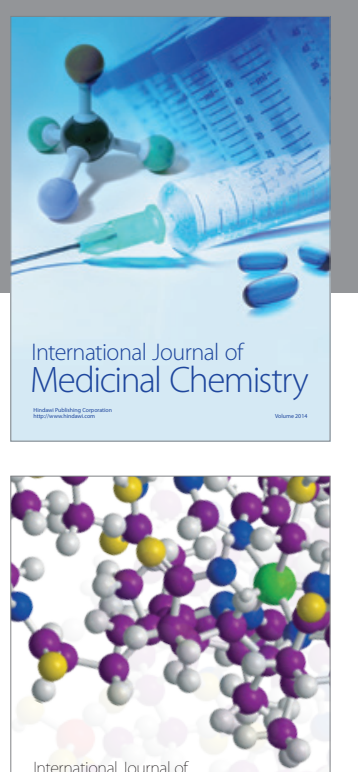

Carbohydrate Chemistry

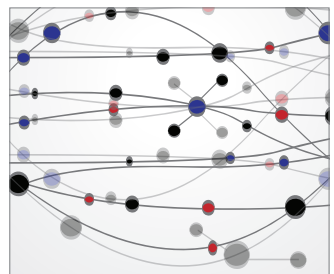

The Scientific World Journal
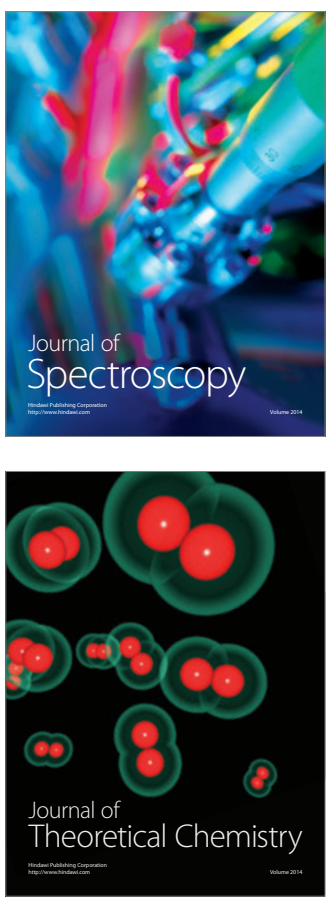
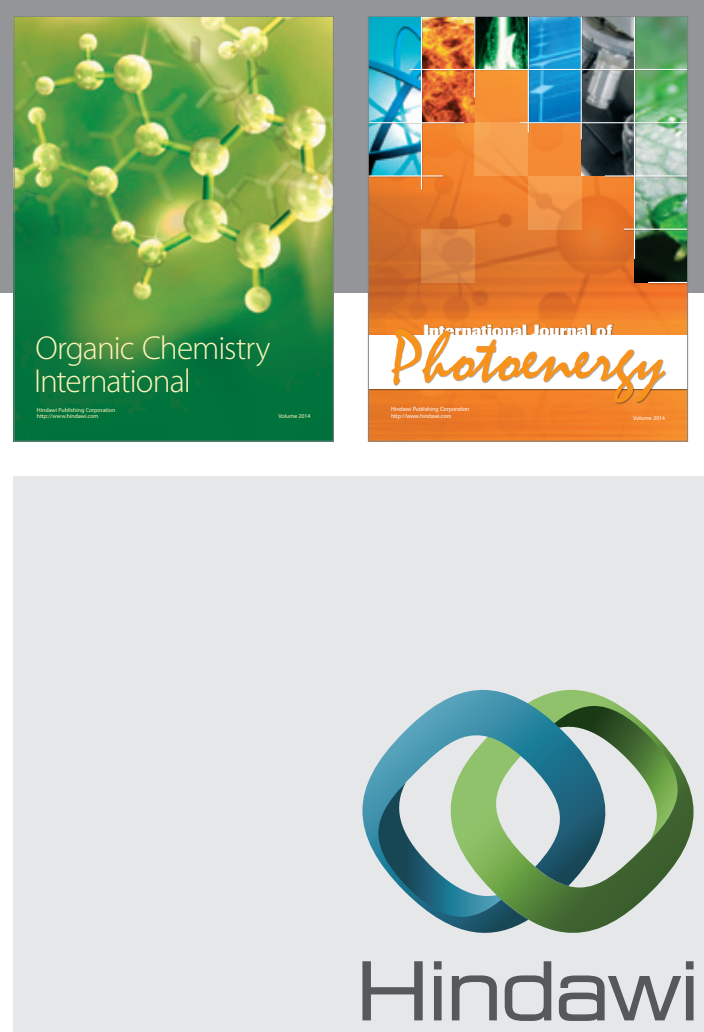

Submit your manuscripts at

http://www.hindawi.com

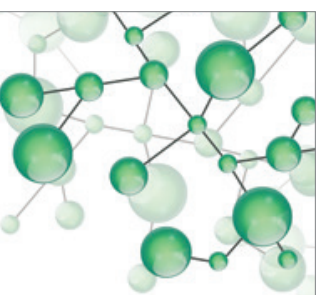

International Journal of

Inorganic Chemistry

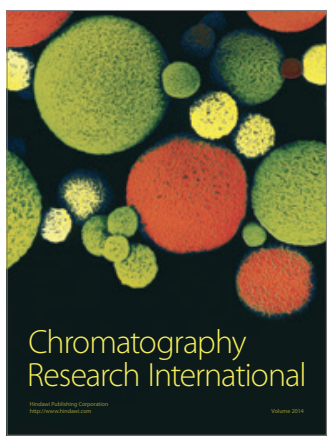

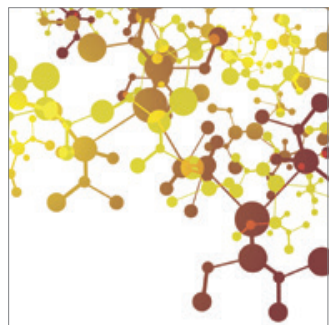

Applied Chemistry
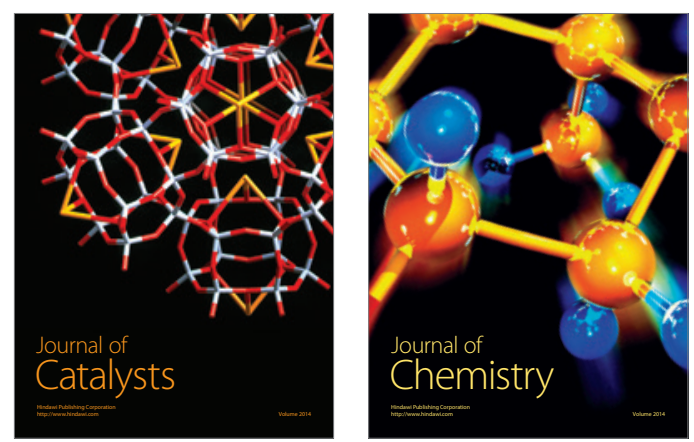
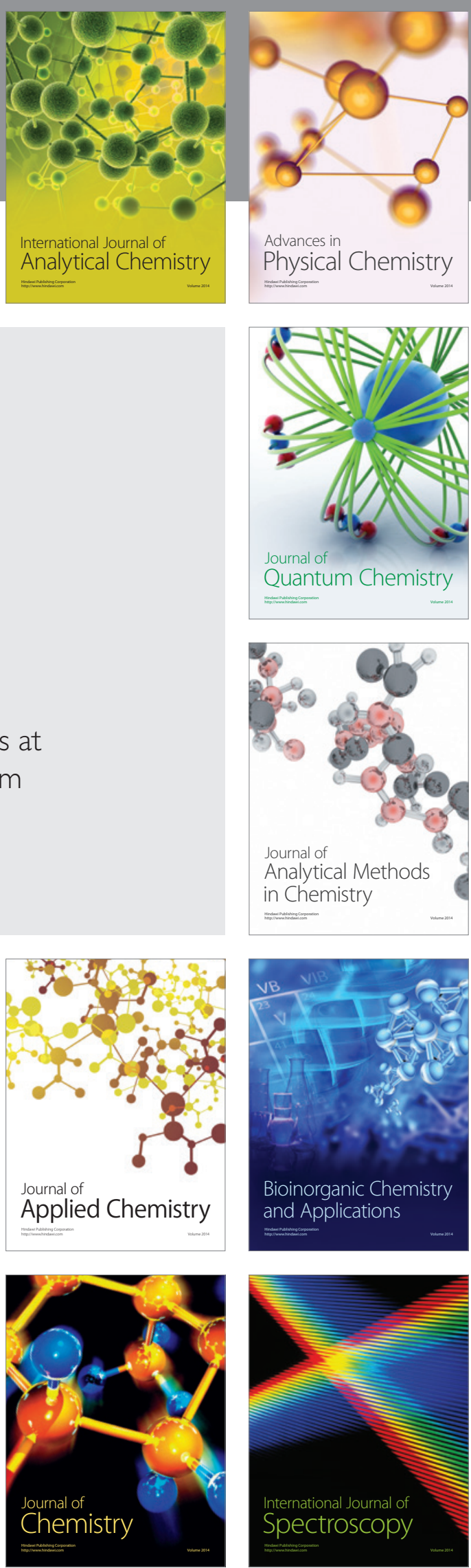